\title{
Preparation and Properties of Soluble Aromatic Polyamides Derived from 2,7-Triptycenedicarbonyl Dichloride
}

\author{
Fumihiko Akutsu, ${ }^{\dagger}$ Mari Inoki, Go SAITo, Tomoko DoI, \\ Yoshio Kasashima, and Kiyoshi NaruchI \\ Department of Applied Chemistry, Faculty of Engineering, Chiba \\ University, Yayoi-cho 1-33, Inage-ku, Chiba 263, Japan
}

(Received September 26, 1997)

KEY WORDS 2,7-Triptycenedicarbonyl Dichloride / Polyamides / Thermal Properties / Solubility /

Aromatic polyamides have good mechanical properties and high thermal resistance, ${ }^{1}$ but indicate low processability. Accordingly, improvement of their processability, in particular, their solubility, has been studied widely. We previously reported aromatic polyamides derived from 9,10-dihydro-9,10-o-benzenoanthracene-1,5diamine (2,7-triptycenediamine; TRIDA) to possess improved solubility as well as high thermal resistance. ${ }^{2}$ Some reports demonstrate that aromatic polyamides having the bulky, rigid, and zigzag unit in the dicarboxylic acid unit exhibit different properties from those of the isomeric polyamides containing the same unit in the diamine moiety. ${ }^{3-7}$ In the present study, novel polyamides 1 were synthesized from 9,10-dihydro-9,10$o$-benzenoanthracene-1,5-dicarbonyl dichloride ${ }^{8}$ (2,7triptycenedicarbonyl dichloride; TRIDIC) and aromatic diamines $\mathbf{2 a}-\mathbf{2 e}$, as shown in Scheme 1, and their properties were investigated. These properties were compared with those of the corresponding isomeric polyamides derived from TRIDA, so that the influence of the polyamide structure on properties could be determined.

\section{RESULTS AND DISCUSSION}

Polyamides 1 were prepared by low-temperature solution polycondensation ${ }^{9}$ of TRIDIC $^{8}$ with aromatic diamines such as 1,3-phenylenediamine (2a), 1,4-phenylenediamine (2b), 4,4'-diaminodiphenylether (2c), 4,4'diaminodiphenylmethane (2d), and 2,2-di[4-(4-aminophenyloxy)phenyl]propane (2e), in 1-methyl-2-pyrrolidone (NMP), as illustrated in Scheme 1. The results are summarized in Table I. All polycondensations proceeded in a homogeneous system. The obtained polymers were white, with IR spectra showing characteristic amide absorptions near 1660 and $1510 \mathrm{~cm}^{-1}$, respectively. Yields were above $86 \%$, and inherent viscosity ranged from 0.42 to $0.97 \mathrm{dl} \mathrm{g}^{-1}$.

The thermal behavior of polyamides $\mathbf{1}$ is shown in Table II. Glass transition temperatures $\left(T_{\mathrm{g}} \mathrm{s}\right)$ were determined by differential scanning calorimetry (DSC). $T_{\mathrm{g}} \mathrm{s}$ of polyamides 1 were high, above $290^{\circ} \mathrm{C}$, except for that of $1 \mathrm{e} . T_{\mathrm{g}} \mathrm{s}$ of 1 virtually depended upon the symmetry and rigidity of the diamine moiety. The low $T_{\mathrm{g}}$ of $1 \mathrm{e}$ was possibly due to the higher flexibility of the diamine $\mathbf{2 e}$ unit. The 2,7-triptycenediyl structure is zigzag and bulky, but has high rigidity. Thus, the introduction of 2,7-
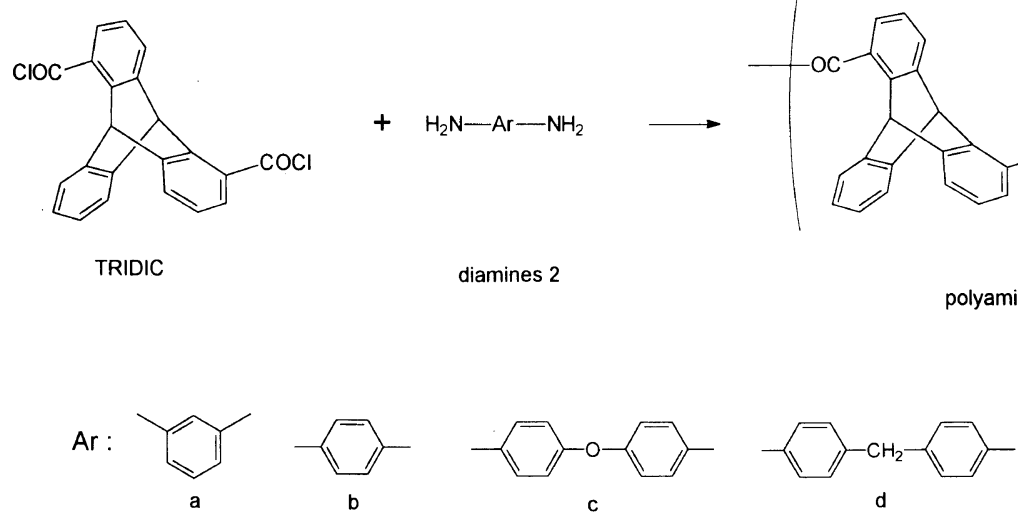

c

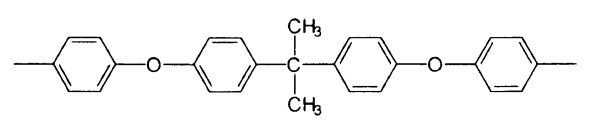

e

Scheme 1.

\footnotetext{
† To whom correspondence should be addressed.
} 
triptycenediyl structure to the dicarboxylic acid unit maintained high $T_{\mathrm{g}} \mathrm{s}$ of aromatic polyamides, and this was attributed to the high rigidity. On all DSC curves,

Table I. Results of polyamide preparation ${ }^{a}$

\begin{tabular}{|c|c|c|c|c|}
\hline \multirow{2}{*}{ Polyamides } & Yield & $\eta_{\mathrm{inh}}^{\mathrm{b}}$ & \multirow{2}{*}{ Color } & \multirow{2}{*}{ Appearance } \\
\hline & $\%$ & $\mathrm{dl} \mathrm{g}^{-1}$ & & \\
\hline 1a & 92 & 0.42 & white & $\mathrm{H}$ \\
\hline 1b & 90 & 0.97 & white & $\mathrm{H}$ \\
\hline 1c & 90 & 0.67 & white & $\mathrm{H}$ \\
\hline 1d & 89 & 0.50 & white & $\mathrm{H}$ \\
\hline $1 e$ & 86 & 0.60 & white & $\mathrm{H}$ \\
\hline 4 & 91 & 0.40 & white & G \\
\hline
\end{tabular}

a Polymerization was carried out at $-18^{\circ} \mathrm{C}$ for $1 \mathrm{~h}$, at $-10^{\circ} \mathrm{C}$ for $1 \mathrm{~h}$, and at room temperature for $3 \mathrm{~h}$. ${ }^{\mathrm{b}}$ Inherent viscosity, measured in concd sulfuric acid $\left(0.50 \mathrm{~g} \mathrm{dl}^{-1}\right)$ at $30^{\circ} \mathrm{C} .{ }^{\mathrm{c}} \mathrm{H}$, homogeneous system; $\mathrm{G}$, gelation.

Table II. Thermal properties of polyamides

\begin{tabular}{|c|c|c|c|c|}
\hline \multirow{2}{*}{ Polyamide } & \multirow{2}{*}{$\frac{T_{\mathrm{g}}^{\mathrm{a}}}{{ }^{\circ} \mathrm{C}}$} & \multirow{2}{*}{$\frac{T_{\mathrm{d}}^{\mathrm{b}}}{{ }^{\circ} \mathrm{C}}$} & \multicolumn{2}{|c|}{ Residual weight in $\%{ }^{c}$} \\
\hline & & & at $600^{\circ} \mathrm{C}$ & at $800^{\circ} \mathrm{C}$ \\
\hline 1a & 314 & 464 & 53 & 48 \\
\hline $1 b$ & 326 & 476 & 47 & 41 \\
\hline 1c & 292 & 445 & 47 & 41 \\
\hline 1d & 290 & 471 & 50 & 45 \\
\hline 1e & 252 & 461 & 40 & 37 \\
\hline 4 & 345 & 475 & 53 & 48 \\
\hline
\end{tabular}

${ }^{a}$ Glass transition temperature, measured by DSC. ${ }^{\mathbf{b}}$ Temperature at $5 \%$ weight loss, determined by TG. ${ }^{\mathrm{c}}$ Determined by TG. no endotherm by melting was observed. The temperatures at $5 \%$ weight loss $\left(T_{\mathrm{d}} \mathrm{s}\right)$ and residual weights were determined by thermogravimetry (TG). $T_{\mathrm{d}} \mathrm{s}$ of 1 ranged between $445^{\circ} \mathrm{C}$ and $476^{\circ} \mathrm{C}$, and residual weights at $600^{\circ} \mathrm{C}$ were above $40 \%$. The high thermal stability of 1 was due to the highly phenylated 2,7-triptycenediyl structure.

The solubility of polyamides 1 in various organic solvents was examined at $2.0 \%(\mathrm{w} / \mathrm{v})$ concentration. The results are tabulated in Table III. Polyamides 1 exhibited good solubility in several organic solvents. In particular, 1a, 1c, and 1d were soluble in tetrahydrofuran (THF) as well as dimethyl sulfoxide (DMSO), $N, N$-dimethylformamide (DMF), NMP, $N, N$-dimethylacetamide, $m$-cresol, pyridine, cyclohexanone at room temperature although showing high $T_{\mathrm{g}} \mathrm{s}$ above $290^{\circ} \mathrm{C}$. 1b also had good solubility for aromatic polyamides, and was soluble in DMSO and pyridine at room temperature while possessing high $T_{\mathrm{g}}$ of $326^{\circ} \mathrm{C}$. 1a, 1d, and 1e were dissolved in NMP up to $20 \%(\mathrm{w} / \mathrm{v})$. Thus, the introduction of the $2,7-$ triptycenediyl structure to the dicarboxylic acid unit greatly improves the solubility of aromatic polyamides without lowering high thermal resistance. The flexible and tough films of $\mathbf{1 a}$ - e were obtained by casting from each $5-20 \%(\mathrm{w} / \mathrm{v})$ polyamide solution in NMP. The $\mathrm{X}$-ray diffraction patterns show that polyamides $\mathbf{1}$ are all amorphous. The bulkiness and low symmetry of the 2,7-triptycenediyl structure led to the amorphous nature, contributing to the improvement of solubility.

$T_{\mathrm{g}} \mathrm{s}$ and solubility of polyamides $1 \mathrm{a}-\mathbf{c}$ were compared with those of the corresponding isomeric polyamides $\mathbf{3}$, containing the 2,7-triptycenediyl structure in the diamine unit, $^{2}$ as shown in Scheme 2. $T_{\mathrm{g}} \mathrm{s}$ of 1 were lower than

Table III. Solubilities of polyamides ${ }^{\mathrm{a}}$

\begin{tabular}{|c|c|c|c|c|c|c|c|c|c|}
\hline Polyamide & THF & $\mathrm{Cy}$ & Py & $m$-Cre & DMAc & NMP & DMF & DMSO & $\mathrm{H}_{2} \mathrm{SO}_{4}$ \\
\hline $1 \mathrm{a}$ & + & + & + & + & + & + & + & + & + \\
\hline $1 b$ & - & $(\mathrm{SW})$ & + & \pm & $(\mathrm{SW})$ & \pm & \pm & + & + \\
\hline 1c & + & + & + & + & + & + & $\bar{t}$ & + & + \\
\hline 1d & + & + & + & + & + & + & + & + & + \\
\hline 1e & + & + & + & + & + & + & + & + & + \\
\hline 4 & - & $( \pm)$ & + & \pm & \pm & SW & + & \pm & + \\
\hline
\end{tabular}

${ }^{a}$ Measured at $2.0 \%(\mathrm{w} / \mathrm{v})$. Data in parenthese were obtained during heating at $60^{\circ} \mathrm{C}$. THF, tetrahydrofuran; Cy, cyclohexanone; Py, pyridine; $m$-Cre, $m$-cresol; DMAc, $N, N$-dimethylacetamide; NMP, 1-methyl-2-pyrrolidone; DMF, $N, N$-dimethylformamide; DMSO, dimethyl sulfoxide. + , soluble; \pm , partially soluble; - , insoluble; SW, swelling.

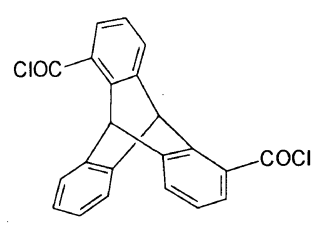

TRIDIC

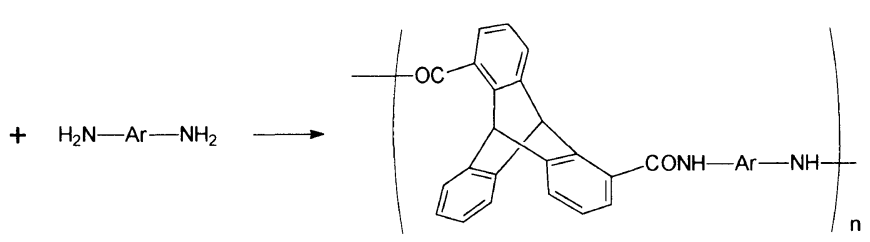

polyamides 1

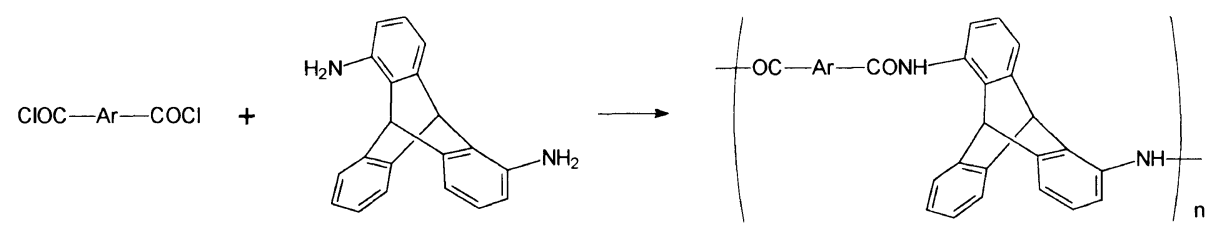

TRIDA

polyamides 3

Scheme 2 . 


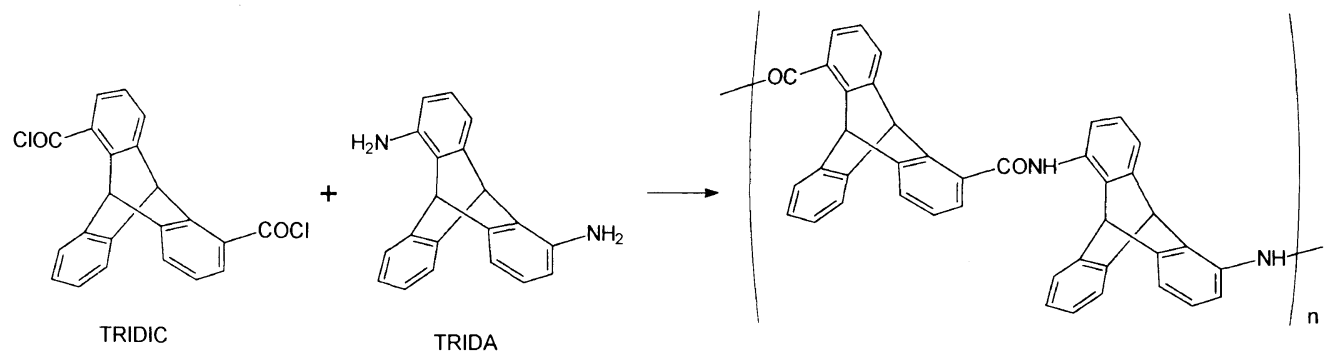

polyamide 4

Scheme 3.

those of $\mathbf{3}$, while solubility of $\mathbf{1}$ was better than that of 3. Imai and Kakimoto et al. reported that there was no obvious difference between the properties of aromatic polyamides containing the rigid, zigzag, and bulky 3,4-diphenyl-2,5-di(1,4-phenylene)thiophene structure in the diamine moiety and those of the corresponding isomeric polyamides having the same structure in the dicarboxylic acid unit. ${ }^{10,11}$ We previously reported there to be no clear difference between the properties of polyamides containing 4,5-di(1,4-phenylene)-2-methyloxazole structure in the diamine moiety and those of the corresponding isomeric polyamides having the same structure in the dicarboxylic acid unit. ${ }^{12}$ But, Dine-Hart et al. reported a polyamide derived from phthaloyl dichloride and 1,4-phenylenediamine indicated lower softening temperature than a polyamide from terephthaloyl dichloride and 1,2-phenylenediamine. ${ }^{3} \mathrm{We}$ previously reported that a polyamide having the 2,3di(1,4-phenylene)quinoxaline structure in the dicarboxylic acid unit indicated lower $T_{\mathrm{g}}$ and solubility than the corresponding isomeric polyamide containing the same structure in the diamine unit, ${ }^{4,5}$ and that a polyamide having 4,4"-o-terphenyldiyl structure in the dicarboxylic acid unit showed higher $T_{\mathrm{g}}$ and lower solubility than the isomeric polyamide having the same structure in the diamine unit. ${ }^{6,7}$ Thus, the relationship of the properties of 1 and 3 with the structures is different from those previously reported. To investigate the differences between the properties of $\mathbf{1}$ and those of $\mathbf{3}$, densities of $\mathbf{1 a}$ and 3a were measured by a density gradient tube. The density of 1a was 1.26 and that of $\mathbf{3 a}$ was 1.28 , that is, the density of $1 \mathbf{a}$ was lower than that of 3a. Thus, packing of polymer chains of $\mathbf{1 a}$ is sparser than that of $\mathbf{3 a}$. This may be due to the weaker intermolecular hydrogen bonding between polymer chains of $\mathbf{1 a}$ for some factor.

Polyamide 4, containing the 2,7-triptycenediyl structure not only in the dicarboxylic acid unit but also in the diamine unit, was synthesized from TRIDIC and TRIDA, as shown in Scheme 3. The results of the polycondensation, thermal behavior, and solubility are shown in Tables I, II, and III, respectively. Gelation occurred during the polymerization. Inherent viscosity was $0.40 \mathrm{dlg}^{-1}$, and yield was $91 \%$. $T_{\mathrm{g}}$ was $345^{\circ} \mathrm{C}$, and $T_{\mathrm{d}}$ was $475^{\circ} \mathrm{C} .4$ was soluble in DMF and pyridine at room temperature. Thus, 4 also exhibited good solubility and high $T_{\mathrm{g}}$. Interestingly, $T_{\mathrm{g}}$ of $\mathbf{4}$ was found to be $c a$. $20^{\circ}$ higher than that of $\mathbf{1 b}$ derived from TRIDIC and 1,4-phenylenediamine, although bulkier and more zigzag $\mathbf{4}$ had as high solubility as $\mathbf{1 b}$. The reason that $\mathbf{4}$ indicated higher $T_{\mathrm{g}}$ than $\mathbf{1 b}$ is not clear. Presumably, since the 2,7-triptycenediyl structure was introduced to the diamine unit as well as to the dicarboxylic acid unit, the polymer structure of $\mathbf{4}$ may be more symmetrical.

It is concluded that the introduction of the 2,7triptycenediyl structure to the dicarboxylic acid unit in the aromatic polyamides improves solubility without loss of high thermal resistance. The polyamides having 2,7triptycenediyl structure in the dicarboxylic acid unit possessed higher solubility and lower $T_{\mathrm{g}} \mathrm{s}$ than the corresponding isomeric polyamides containing the same structure in the diamine unit due to the sparser packing of polymer chains.

\section{EXPERIMENTAL}

\section{Polycondensations}

TRIDIC was prepared as reported by Kuritani et al. ${ }^{8}$ Diamines 2 were obtained commercially, and recrystallized before polymerization. A typical procedure of the polyamide synthesis (1c) is as follows: In a 10-ml reaction tube equipped with a mechanical stirrer, and a nitrogen gas inlet having a calcium chloride tube were placed $0.200 \mathrm{~g}$ of diamine $2 \mathrm{c}(1.00 \mathrm{mmol}), 0.103 \mathrm{~g}$ of dried lithium chloride $(2.43 \mathrm{mmol})$ and $1.28 \mathrm{ml}$ of NMP. After the salts were dissolved, the solution was cooled to $-18^{\circ} \mathrm{C}$. $0.379 \mathrm{~g}$ of TRIDIC $(1.00 \mathrm{mmol})$ and $0.72 \mathrm{ml}$ of methyl oxirane were added, and the mixture was stirred at $-18^{\circ} \mathrm{C}$ for $1 \mathrm{~h}$, at $-10^{\circ} \mathrm{C}$ for $1 \mathrm{~h}$, and at room temperature for $3 \mathrm{~h}$. The reaction mixture was poured into aqueous methanol (1/1 by volume) for precipitation. The product was washed with methanol. Yield $90 \%$. $\eta_{\text {inh }}=0.67 \mathrm{dlg}^{-1}\left(0.50 \mathrm{~g} \mathrm{dl}^{-1}\right.$ in $\mathrm{H}_{2} \mathrm{SO}_{4}$ at $\left.30^{\circ} \mathrm{C}\right)$. IR (film) $1668,1500 \mathrm{~cm}^{-1}$ (amides I, II). Anal. Calcd for $\left(\mathrm{C}_{34} \mathrm{H}_{22} \mathrm{O}_{3} \mathrm{~N}_{2}\right)_{n}(506.6)_{n}: \mathrm{C}, 80.62 \% ; \mathrm{H}, 4.38 \% ; \mathrm{N}$, $5.53 \%$. Found: C, $78.17 \%$; H, $4.38 \%$; N, $5.30 \%$.

Other polyamides were synthesized by a similar procedure.

\section{Measurements}

$T_{\mathrm{g}} \mathrm{s}$ were determined by DSC (Rigaku DSC 8230D). $T_{\mathrm{d}} \mathrm{s}$ and the residual weights were found by TG (MAC Science TG-DTA 2000). The thermoanalytical measurements were performed under the following conditions: heating rate, $10 \mathrm{~K} \mathrm{~min}^{-1}$; under a nitrogen atmosphere. $T_{\mathrm{g}} \mathrm{s}$ were determined by second scannings using virgin samples. IR spectra were recorded on a Hitachi 270-30 spectrophotometer. Wide angle X-ray diffraction patterns were obtained for specimens on a Rigaku XG Xray diffraction apparatus with $\mathrm{Cu}-\mathrm{K}_{\alpha}$ radiation $(25 \mathrm{kV}$, $10 \mathrm{~mA}$ ). The densities of the polyamides were measured 
by means of a density gradient tube (water/sodium iodide at $23^{\circ} \mathrm{C}$ ) according to the procedure of JIS K 7112 .

Acknowledgments. The authors thank SUMIBE TECHNO-RESEARCH Co. Ltd., for measurement of polyamide film density. The authors are grateful to $\mathrm{Mr}$. Tadao Kuramochi, Chemical Analysis Center, Chiba University, for carrying out the elemental analysis.

\section{REFERENCES}

1. P. E. Cassidy, "Thermally Stable Polymers," Marcel Dekker, New York, N.Y., 1980

2. Y. Kasashima, T. Kaneda, G. Saito, F. Akutsu, K. Naruchi, and M. Miura, Macromol. Chem. Phys., 195, 2693 (1994).

3. R. A. Dine-Hart, B. J. C. Moore, and W. W. Wright, J. Polym. Sci., B, 2, 369 (1964).
4. F. Akutsu, H. Hirata, H. Hayashi, M. Miura, and K. Nagakubo, Makromol. Chem., Rapid Commun., 6, 215 (1985).

5. F. Akutsu, K. Matsuo, K. Naruchi, and M. Miura, Polymer, 30, 182 (1989).

6. Y. Kasashima, K. Yamamoto, N. Ando, F. Akutsu, K. Naruchi, and M. Miura, Polym. J., 26, 1298 (1994).

7. Y. Kasashima, H. Kumada, K. Yamamoto, F. Akutsu, K. Naruchi, and M. Miura, Polymer, 36, 645 (1995).

8. M. Kuritani, Y. Sakata, F. Ogura, and M. Nakagawa, Bull. Chem. Soc. Jpn., 46, 605 (1973).

9. P. W. Morgan, "Condensation polymers by Interfacial and Solution Methods," Interscience, New York, N.Y., 1965.

10. Y. Imai, N. N. Malder, and M. Kakimoto, J. Polym. Sci., Polym. Chem. Ed., 23, 1797 (1985).

11. M. Kakimoto, Y. S. Negi, and Y. Imai, J. Polym. Sci., Polym. Chem. Ed., 23, 1787 (1985).

12. F. Akutsu, M. Inoki, K. Sunouchi, Y. Sugama, Y. Kasashima, K. Naruchi, and M. Miura, Polymer, in press. 